\title{
Nasopharyngeal Nonkeratinizing Carcinoma
}

National Cancer Institute

\section{Source}

National Cancer Institute. Nasopharyngeal Nonkeratinizing Carcinoma. NCI Thesaurus.

Code C7373.

A nasopharyngeal carcinoma characterized by the lack of keratinization and the presence of a dense lymphoplasmacytic infiltrate. It is subdivided into undifferentiated and differentiated types, based on the cytologic features of the malignant cells. The undifferentiated type is characterized by the presence of cells with large vesicular nuclei with prominent nucleoli and a syncytial pattern of growth. The differentiated type is characterized by the presence of smaller cells and cellular stratification reminiscent of transitional cell carcinoma. While morphologically distinct, both types have similar clinical presentation and prognosis. 